\title{
Using Multi-Function Teams in Business Process Design and Development: A Case Study
}

\author{
Mohsen Sharifi (E-mail: msharifi@fullerton.edu), California State University Fullerton \\ Vijay Karan (E-mail: vkaran@fullerton.edu), California State University Fullerton \\ Zafar Khan (E-mail: zkhan@emich.edu), Eastern Michigan University
}

\begin{abstract}
This paper presents the use of multifunction teams to design, develop and implement a merger and acquisition $(M \& A)$ process at a major Midwest utility company. Since the passage of the "wheeling" act in 1992, many states have passed laws that would free utility companies from regulatory requirements altogether. A predicted outcome of this deregulation process already being witnessed is the growing consolidation and shakeout in the utility industry. In order to position itself and gain competitive advantage in the new deregulated business environment, a major Midwest utility company charged a multifunction team to design, develop and implement a $M \& A$ process. Details of team structure, process, and the developed merger and acquisition process are discussed.
\end{abstract}

\section{Introduction}

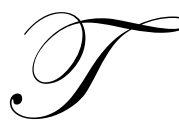

he deregulation of the electric utility industry is imposing new strategic, organizational, managerial, and information demands on the electric utility companies. Utility companies have to focus on cash flow and other market economic measures. They have to develop advertising and marketing programs that create a brand image. They also need to understand their customers' needs and how to meet them. The transition from a protected industry, not familiar with market processes is not easy for many electric utility companies. As a result the electric utility industry is in a state of flux. A predicted outcome of this deregulation process already underway is the growing consolidation and shakeout. Statistics are difficult to obtain but according to one Goldman Sachs analyst, in 1997 there were 14 pending mergers with a total market value of $\$ 60$ billion involving electric utilities. The merger and acquisition (M\&A) activity is expected to further intensify.

While motives for M\&A are many and varied, one of the primary reasons is the change that occurs in the nature of industries with deregulation. For instance, many M\&A were reported in the United States after the deregulation of airlines and telecommunication industry. The recent deregulation of the $\$ 212$ billion a year electric utility industry is having a profound impact on the electric utility companies. As a result, one could expect similar restructuring for this industry as has been observed for airlines and cable companies. In fact, the utility companies are among the most active industries both in terns of dollar value and the number of deals, a company in Cincinnati has set a goal to be one of the five biggest energy traders in the United States [Mergers \& Acquisitions, July-August 1999]. Unfortunately, mergers in rapidly consolidating industries are markedly unsuccessful [Wall \& Wall 2000]. A January 2000 Economist report showed that eleven out of twelve big drug company mergers since 1970 resulted in a subsequent loss of market share [Wall \& Wall 2000, p. 5]. To enhance the probability of success in a merger or acquisition, it is important that a careful strategic analysis be made.

As the goals are set, alliances are formed and deals are announced, there appears to be a need for streamlining business restructuring and M\&A process. M\&A process requires a delicate balance. On one hand, the amount of resources at stake is too high. Thus, the companies involved should exercise a high degree of caution when engaged in restructuring. On the other hand, being cautious requires a careful analysis of each situation. This 
may take too much time and resources, in turn resulting in loss of many opportunities. To ensure that this delicate balance is maintained a major Midwest utility company established a multifunction team to design and develop a M\&A process that was implemented and lead to a successful mega merger.

\section{Strategic Role Of Multifunction Teams}

Recently multifunction teams have helped organizations in many strategic areas. Functioning as a member or a leader of a team has become one of the desired skill in organizations which have transformed from traditional hierarchical to more flattened network organizations. For instance the American Institute of Certified Public Accountants [AICPA, 2001] recently had advocated a team skill as one of the important "functional" skills necessary for the entrants to accounting profession. The summary of the core competencies that have team implication is listed in Exhibit 1.

Exhibit 1 - Core Competencies Team-Related

\begin{tabular}{|l|l|}
\hline FUNCTIONAL & \\
\hline PERSONAL & \\
\hline Interaction & Recognizes the value of working within diverse, cross-functional teams \\
\hline & Interacts and cooperates productively and maturely with others \\
\hline & Facilitates free expression and constructive activities of others \\
\hline & Commits to achievement of common goals when working on a team \\
\hline & Accepts suggestions and guidance of team leaders and other members \\
\hline & Recognizes and accommodates the protocols and expectations of teams \\
\hline
\end{tabular}

The use of multifunction teams advocated by quality gurus to solve product/process quality problems has extended to virtually all areas. Tom Peters [1990] notes that many companies are reducing excessive layers of management and scrunching people together in multifunction teams to provide fast, specialized solutions to customers' needs. This approach helped Xerox increase customer satisfaction by $38 \%$ in the first five years of using multifunction teams. ${ }^{1}$ Other companies have successfully used multifunction teams for assuring supplier quality [DeRose 1983], business process reengineering of IT projects [Lisburn \& Baxter 1994], new product development [Takeuchi \& Nonaka 1986] and business improvement program [Crabb 1990].

Traditionally, M\&A activity has been the domain of the executive office with limited support from planning staff. Lacking expertise and for confidentiality reasons some companies prefer to use outside consultants-one of the many accounting, finance and brokerage firms that specialize in M\&A. In other words, historical emphasis in M\&A activity has been to limit the number of people and functions involved. In the current globally dynamic business environment, this is a recipe for failure. For successful M\&A activity it is important that people at all levels and all functional areas be involved because M\&A activity impacts all areas of the business. Realizing that the success of any future M\&A depends upon people from different areas working together to realize potential synergies, a major Midwest utility company put together a multifunction team with the charge of developing and implementing a M\&A process. Team members consisted of people from corporate planning, accounting and finance, operations, engineering, sales and marketing, human resources, and the executive office.

Further, when M\&A is defined as a process, it is more logical for the management accountants to be engaged in the process as a valuable member of the multifunction team. Management accountants, through their financial due diligence, play a crucial role in overcoming executive fear of something going wrong during the M\&A process [Callahan 1991]. In the following sections M\&A process developed by the multifunction team at a major Midwest utility company is discussed. The process is generic in nature and can be applied to other industries as well. The design and development of the M\&A process was spearheaded by a group of management accountants including an outside expert and involved many staff members from other areas as mentioned above. Activities included in the processes would allow the company to (1) identify and evaluate M\&A candidates and/or other business restructuring alternatives; (2) negotiate a more favorable deal for the company; (3) systematically close and 
implement the M\&A or business restructuring process, and (4) save valuable resources of the company which would have otherwise been wasted on a lengthy and inefficient process.

\section{Merger And Acquisition Process}

The conceptual view of the developed M\&A process is demonstrated in Exhibit 2. As soon as a company decides upon an M\&A or business restructuring strategy, it should form a high level multifunction steering committee appropriately called business combination committee, business acquisition committee or business restructuring committee. This committee generally reports to the Chief Executive Officer (CEO) or the president of the company. Among the individuals that are appointed to this committee are: a representative from corporate strategy group, a representative from the business unit involved in M\&A or restructuring, a representative from accounting and finance group, a representative from the legal department and a representative from business development group.

One of the primary tasks of the committee is to set criteria or benchmarks for the evaluation process. These benchmarks are expressed in terms of stock market capitalization, current ratio, and liabilities to stockholders equity ratio and the rate of growth in revenue or earnings. To set these benchmarks, the committee generally reviews the industry profile. It is also the committee's prerogative to utilize organized data sources such as Standard \& Poor's, Compustat, Dun a Bradstreet and other types of appropriate services available. Setting these benchmarks properly would facilitate the process of eliminating the unacceptable candidates.

The committee also develops a list of considerations relevant to the selection and evaluation of business combination or restructuring. For instance, one of the considerations is the form that a business may assume i.e. merger, consolidation, stock acquisition, asset acquisition, joint venture and other types. Another consideration is whether the transaction will be accounted for as Pooling or as Purchase as defined in Generally Accepted Accounting Principles.

It is the responsibility of this committee to define key inputs of each step of the process, key processes of M\&A or business restructuring, and key outputs of each of the processes. The main deliverable of the steering committee is the development and creation of strategies to carry out M\&A or business restructuring. To accomplish this objective, the committee uses corporate vision statement, corporate goals and objectives, and corporate business strategies. These are the input to this process, so that the committee could develop specific strategies pertinent to M\&A or business restructuring. Generally, the corporate vision statement and strategies are established at the highest level of the organization, by the board of directors.

The M\&A or business restructuring strategies developed by the multifunction steering committee will drive the process into two distinct paths. The first path is the financial review process. The high level multifunction steering committee normally recruits/appoints qualified staff members to another multifunctional team that is charged with a specific business combination task. The financial review process team consists mainly of personnel from various accounting and finance subspecialties such as, financial planning, business valuation, cost and systems, and corporate tax experts who carry out this process. The team should also include representatives from legal department as well as market or industry analysts. 


\section{Exhibit 2 - Conceptual View of M\&A Process}

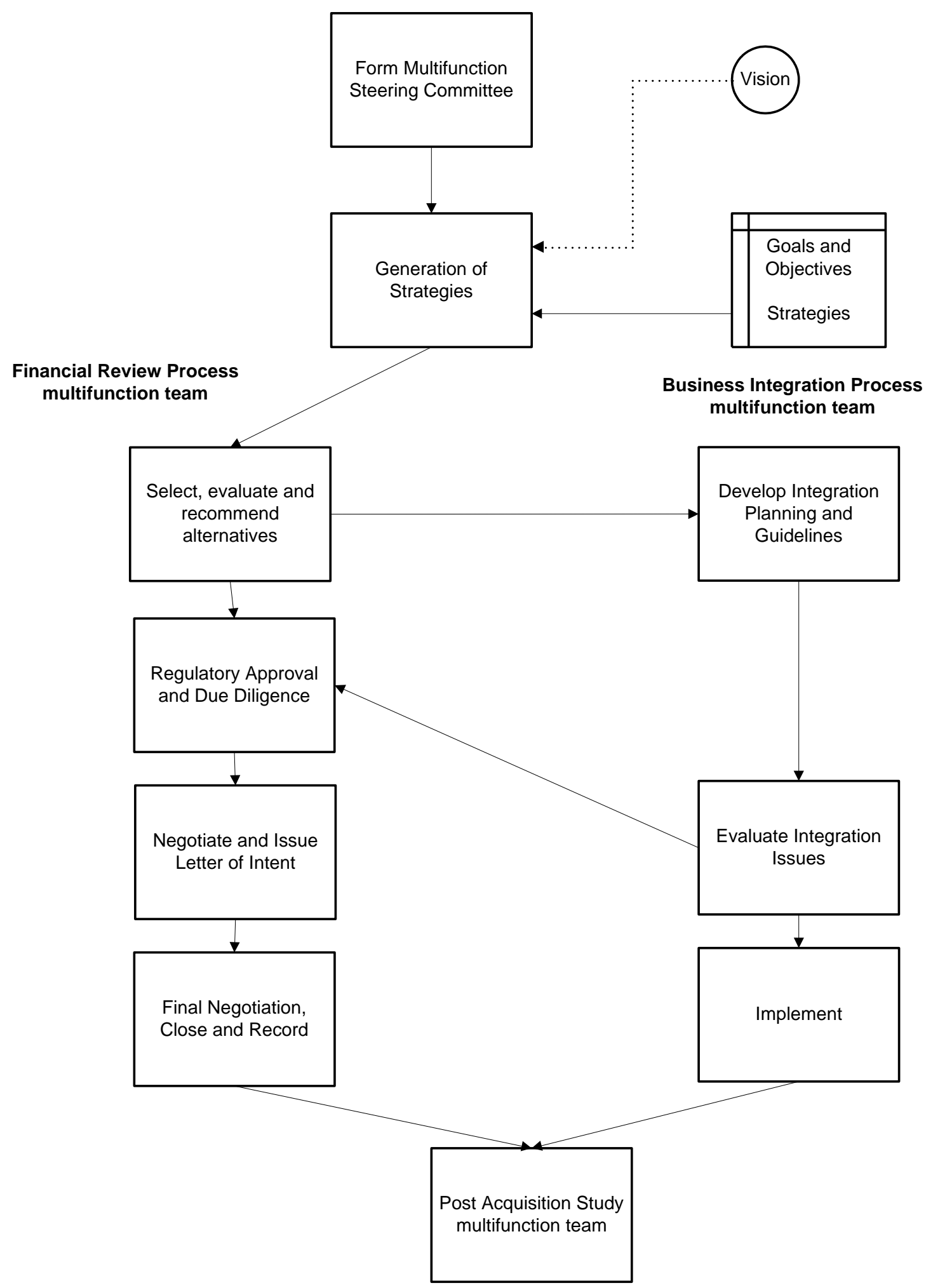


This process involves selection of the candidates for business combination, evaluation of the candidates based on the acquisition strategy developed and approved by the steering committee, short listing them and eventually recommending the candidates for a more serious evaluation. If the high level multifunction steering committee found a candidate acceptable, then a due diligence review is ordered. At this stage it is normal for the parties to negotiate more specific points. Full due diligence will start for the candidates that have received the letter of intent. The multifunctional team will make its final recommendation to the steering committee at this time. A favorable recommendation will trigger the negotiation process and the draft agreement will be generated. The board of directors approves the acquisition agreement and the deal will be closed after the board approval. The closing documents are the source for recording the transaction in the books at this time. If there are any post acquisition issues, they will be dealt with at this stage. For example, regulatory approval may be required for certain types of M\&A. If required, approval is obtained at this stage of the process. Approval of the regulatory authorities will allow the parties of a given transaction to perform the final negotiation, close and record the deal in their respective books.

The second path is the business integration process, also carried out by another multifunction team. Of necessity the composition of this team is broader, it also includes representatives from operations, engineering, information technology, sales and marketing, and human resources. This process includes the steps for the development of an integration plan and the creation of the integration related issues. At this stage, various cultural and other fitness or alignment of the M\&A or business restructuring would be evaluated.

When the closing is accomplished and the business combination is fully implemented, a post acquisition study should be required. The post acquisition audit team should include personnel from all affected areas. The post acquisition study is performed to evaluate the merit of the actions taken throughout the process. World-class companies generally document the entire process for any successful and unsuccessful M\&A or business restructuring activity. This strategy is adopted in line with the creation of a learning organization. The company will use this documentation to learn from the past; what type of strategy has been valid and which particular strategy resulted in failure.

\section{Conclusion}

Approaching organizational tasks as part of a process will have many advantages that are documented in management accounting literature. Among the ones related to this area are enhanced focus on the issue at hand and more effective execution of organizational strategies; facilitation of effective and timely decision making; facilitation in assignment of responsibilities; facilitation of tracking and monitoring of progress; diminishing probability of disputes in this type of deals; increasing chances of favorable resolution in case of dispute and implementation of continuous improvement policy as it relates to M\&A and business restructuring process improvement.

This paper presents an exciting opportunity for management accountants to participate as a valuable member of multifunction teams in the development and implementation of M\&A process. The electric utilities industry is used as an example due to major changes taking place because of deregulation. Virtually all utilities are devising some form of M\&A strategies to form strategic alliances and critical mass essential for survival in the highly competitive market economy. It also highlights the growing involvement of multifunction teams in strategic issues facing businesses. In particular, the development of a formal M\&A process at a major Midwest utility using a multifunction team.

The developed M\&A process is presented Responsibilities of multifunction committees and other participants in the process are discussed. Detailed flow chart is also presented that may be used as is or modified to fit individual business situations. 


\section{References}

1. American Institute of Certified Public Accountants (AICPA), Accounting Education Executive Committee. Core Competency Framework for Entry into the Accounting Profession, (1999), New York: AICPA, Internet version (2001).

2. Callahan, John P., "How Illogical Fears can Stymie a Good Acquisition", Mergers and Acquisitions, v25n5, March/April 1991, pp. 52-54.

3. Crabb, Steve, "Ringing in the Changes", Personnel Management, London, Aug 1990, pp. 38-41.

4. $\quad$ DeRose, Louis J., “Assuring Supplier Quality”, Purchasing World; Barrington, Jul 1983, p. 42-43.

5. Lisburn, David and Stephen Baxter, "Applying business-process reengineering to IT project development", International Journal of Project Management, Guildford; Nov 1994, pp. 205-209.

6. Peters, Tom, "Multifunction Teams", at http://www.tompeters.com/toms_world/t1990/042090-when.asp.

7. Takeuchi, Hirotaka and Ikujiro Nonaka, "The New Product Development Game", Harvard Business Review, Boston, Jan/Feb 1986, pp. 137-146.

8. Wall, Stephen J. and Shannon R. Wall, The Morning After: Making Corporate Mergers Work after the Deal is Sealed, Perseus Publishing, Cambridge, Massachusetts, 2000.

Notes 